Vietnam Journal of Earth Sciences 37 (2015) 299-306

Vietnam Academy of Science and Technology
Vietnam Journal of Earth Sciences
Website: http://www.vjs.ac.vn/index.php/jse

\title{
Finding nanotubular halloysite at Lang Dong kaolin deposit, Phu Tho province
}

\author{
Bui Hoang Bac*, Nguyen Tien Dung \\ Hanoi University of Mining and Geology, Hanoi, Vietnam
}

Accepted 9 December 2015

\begin{abstract}
Halloysite obtained from Lang Dong kaolin deposit, Phu Tho province was characterized by X-ray diffraction (XRD), scanning electron microscopy (SEM), and transmission electron microscopy (TEM). XRD analysis showed that halloysite (10 $\AA$ and $7 \AA ̊$ basal spacing) and kaolinite coexist in sample of size fractions $<2 \mu \mathrm{m}$. SEM and TEM analyses showed that the halloysite has hollow nanotube structures with typical outer diameter of $0.08 \div 0.30 \mu \mathrm{m}$ and length of $0.60 \div 6.00 \mu \mathrm{m}$. The mean outer diameter and length are 0.17 and $2.48 \mu \mathrm{m}$, respectively. Semi-quantitative analysis using scanning electron microscopy with energy dispersive Xray spectroscopy (SEM/EDS) showed that the sample consists mainly of $\mathrm{Al}_{2} \mathrm{O}_{3}$ and $\mathrm{SiO}_{2}$. Result of formamide (FA) treatment showed that under size fraction $<2 \mu \mathrm{m} 50 \mathrm{wt} \%$ of the sample was taken by halloysite. The study elucidates the characteristics of mineral components, allowing for more efficient use of this resource.
\end{abstract}

Keywords: Halloysite, kaolinite, nanotube, clay minerals, Lang Dong deposit.

C2015 Vietnam Academy of Science and Technology

\section{Introduction}

Halloysite was first described by Berthier as a dioctahedral 1:1 clay mineral of kaolin group (Berthier, 1826). The mineral has wide occurrences in both weathered rocks and soils, whose formation is due to hydrothermal alteration of a wide variety of both igneous and non-igneous rock types (Churchman, 2000). The structure and chemical composition of halloysite are similar to those minerals of kaolin group (kaolinite, halloysite, dickite or nacrite) but the unit layers of halloysite are separated by a monolayer of water molecules (Churchman \& Carr, 1972, 1975).

Halloysite can assume a variety of particle morphologies such as short-tubular, large-tubular and spheroidal and platy shapes (Wada \& Mizota,

${ }^{*}$ Corresponding author, Email: buihoangbac@humg.edu.vn
1982, Churchman \& Theng, 1984). The most common morphology of halloysite is a nanotubular. The tubular shape can be considered as rolled kaolin sheets with inner diameter of $1 \div 30$ $\mathrm{nm}$, outer diameter of $30 \div 50 \mathrm{~nm}$ and length of 100-2000 nm (Mingliang et al., 2010). The internal side of halloysite is composed of $\mathrm{Al}_{2} \mathrm{O}_{3}$ while the external is mainly $\mathrm{SiO}_{2}$. Kaolinite sheets were rolled into tubes because of the strain caused by lattice mismatches closely aligned silicon dioxide and aluminum oxide layers (Fig. 1) (Nicolini et al., 2009).

Halloysite can occur mainly in two different groups: the hydrated form with the minimal formula $\mathrm{Al}_{2} \mathrm{Si}_{2} \mathrm{O}_{5}(\mathrm{OH})_{4} \cdot 2 \mathrm{H}_{2} \mathrm{O}\left(\mathrm{a} \mathrm{d}_{001}\right.$ spacing of 10 $\AA$ ) and the dehydrated form with the minimal formula of $\mathrm{Al}_{2} \mathrm{Si}_{2} \mathrm{O}_{5}(\mathrm{OH})_{4}\left(\mathrm{a} \mathrm{d}_{001}\right.$ spacing of $7 \AA$ ). The $10 \AA$ halloysite is usually found in humid regions and the hydrated halloysite is in areas with 
B. H. Bac and N. T. Dung/Vietnam Journal of Earth Sciences 37 (2015)

dry climate. Under ambient conditions of temperature and humidity or moderate heating at $40^{\circ} \mathrm{C}, 10 \AA$ halloysite can be converted quickly into $7 \AA$ form (Kohyama et al., 1978). Halloysite had been reported to be formed by alteration of feldspars, biotite, and volcanic glass. Halloysite derived from volcanic glass has a spheroidal morphology, whereas the dominant morphology of tubular halloysite derived from crystalline minerals such as feldspars and micas although other forms had been observed (Yariv and Shoval, 1976).
Generally, the relative abundance of halloysite with respect to kaolinite decreases with increasing weathering degree (Joussein et al., 2004). Both halloysite and kaolinite were usually presented in kaolin deposits; therefore, it was difficult to distinguish them because of their structural similarity, especially when the halloysite component appeared in the dehydrated form. Intercalation of formamide was used to differentiate dehydrated halloysite from kaolinite (Churchman \& Theng, 1984, Sunaree et al., 2011).

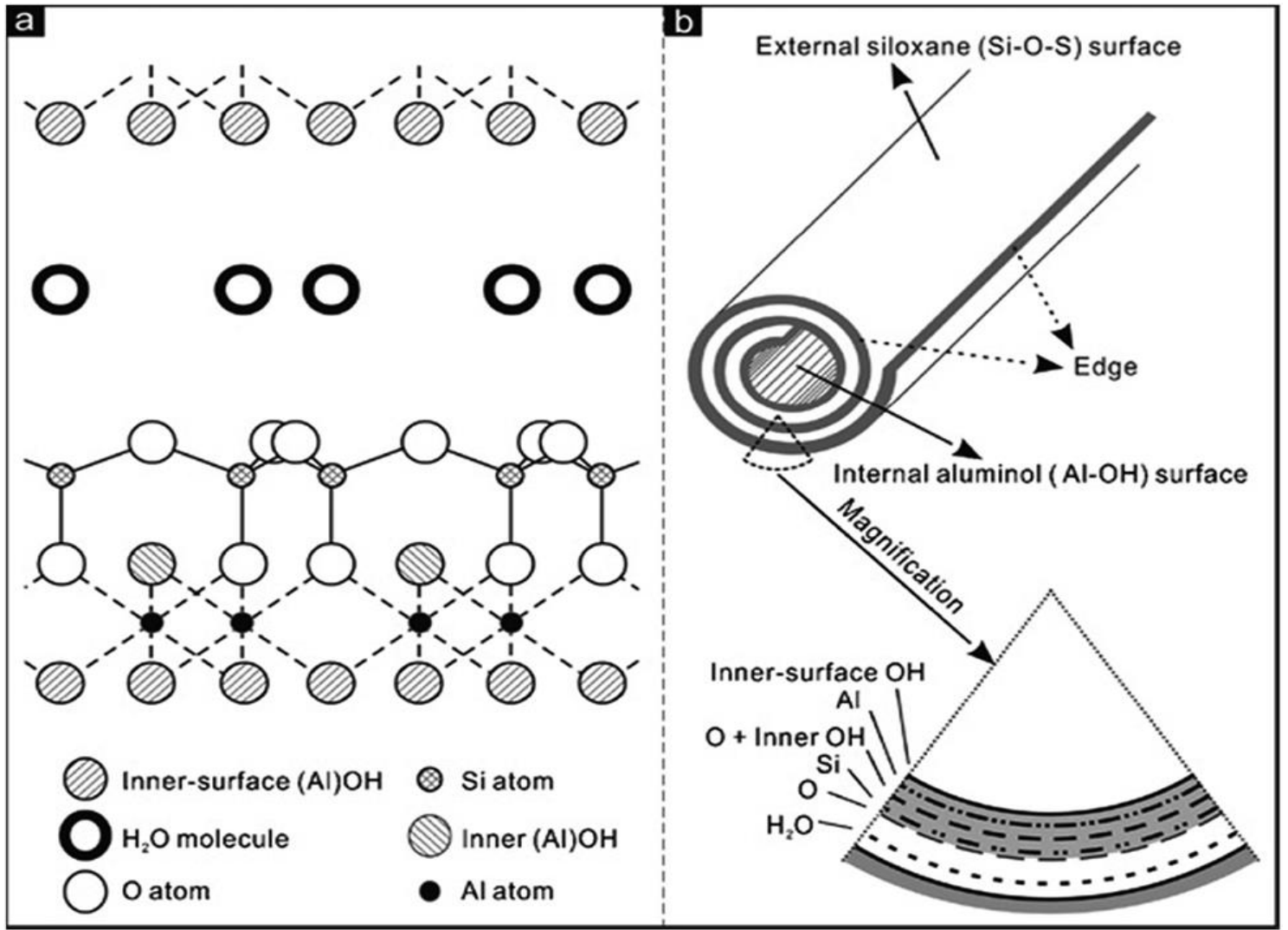

Fig. 1. Schematic diagrams of of the crystalline structure halloysite (a) and the structure of a halloysite nanotube (Ghanbari et al., 2015)

Historically, halloysite was used to produce high quality ceramics in manufacturing of porcelain, bone china, fine china and crucible products. However, recently, due to having novel important properties such as catalytic, large reactive surface area, modifiable in structure and surface properties, magnetic, hollow structures, non-toxic, durable with high mechanical strength, inexpensive and so on, nanotubular halloysites have been used in many new applications by scientists and engineerings. For examples, halloysite nanotubes can be used in anticancer therapy, sustained delivery for certain agents, as template or nanoreactor for biocatalyst, in personal care, cosmetics and even environment protection (Ravindra et al., 2012; Deepak \& Agrawal, 2012). 
Vietnam Journal of Earth Sciences 37 (2015) 299-306

This study aims at characterizing halloysite nanotubes from the Lang Dong kaolin deposit, Phu Tho Province. Characteristics of halloysite were determined using XRD under difference experimental conditions of ethylene glycol, heating and formamide treatment. Other characteristics analysis was performed using scanning electron microscopy with energy dispersive X-ray spectroscopy (SEM/EDS) and transmission electron microscopy (TEM). The obtained results have shed the light on the characteristics of mineral components, thereby allowing for more efficient use of this resource.

\section{Methodology}

\subsection{Study area and sample preparation}

Halloysite samples were collected from the weathered part in Lang Dong kaolin deposit, Phu
Tho Province. The geological features of the deposit are simple with the distribution of the Thach Khoan Formation and Quaternary sediments (Fig. 2). Three pegmatite bodies were found in the area and their dip angles are about $50-80^{\circ}$. Weathering layer was quite thick and the thickness can be up to $50 \mathrm{~m}$ (Nguyen \& Nguyen, 2006). The bulk sample was taken in the weathering part with white, pinky white in color.

The bulk sample was first dissolved in deionized water. A portion of $<2 \mu$ m clay sample fraction was obtained using decantation method. The size fractions $<2 \mu \mathrm{m}$ were mounted as oriented aggregate mounts. Those can be used for other treatments including air drying, glycolation with ethylene glycol, step heating to $350^{\circ} \mathrm{C}$ and to $550^{\circ} \mathrm{C}$, and formamide intercalation (Poppe et. al., 2001)
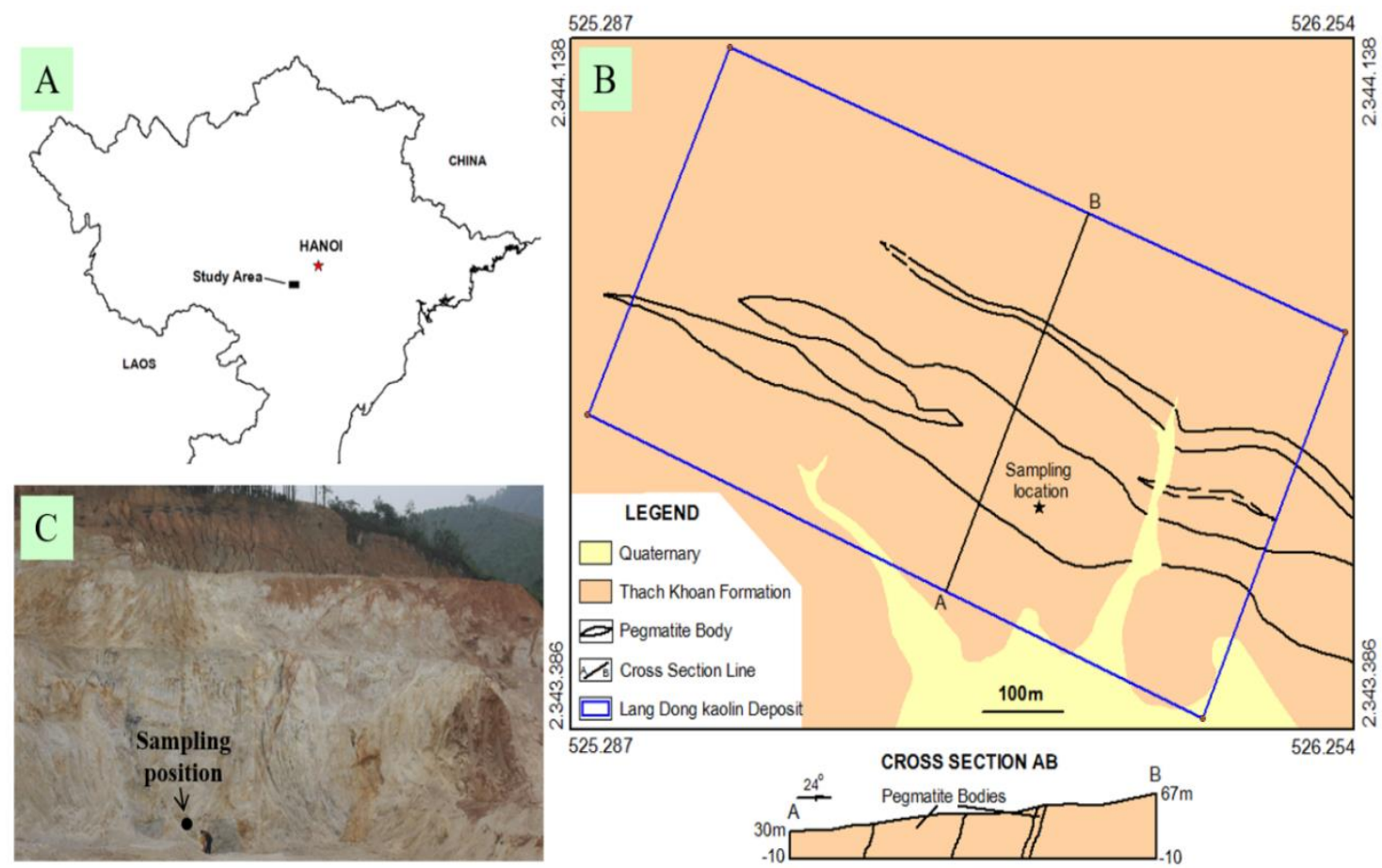

Fig. 2. Study area (A), simplified geological map (B) (Nguyen \& Nguyen, 2006) and the mining pits (C) of Lang Dong kaolin deposit

\subsection{Analytical methods}

X-ray powder diffraction patterns of the samples with different conditions were measured using a D5005 Siemens model powder diffractometer with $\mathrm{Cu}-\mathrm{K} \alpha$ radiation at $40 \mathrm{kV}$ and $30 \mathrm{~mA}$ at the Faculty of Physics, Hanoi University of Science, Vietnam National University. All 
B. H. Bac and N. T. Dung/Vietnam Journal of Earth Sciences 37 (2015)

samples were scanned from 3 to $70^{\circ}$ at a goniometer rate of $2 \theta=2^{\circ} \mathrm{min}^{-1}$. Clay minerals were identified by using the software named Joint Committee of Powder Diffraction Standards (JCPDS). The relative percentages of the synthesized minerals were calculated by using FULLPAT method for XRD patterns (Chipera \& Bish, 2002).

The morphological properties and major elements in the samples were examined by using the scanning electron microscope (SEM - Quanta 450) with energy dispersive X-ray spectroscopy (EDS), at the Geosciences Laboratory, Hanoi University of Mining and Geology. TEM images were obtained by a JEM 1010, JEOL microscope operating at $160 \mathrm{kV}$ at the Vietnam National Institute of Hygiene and Epidemiology, Hanoi. The samples were suspended in ethanol deposited drop-wise and evaporated on 200 mesh copper grids covered with amorphous carbon.

\section{Results and Discussion}

\subsection{X-ray Diffraction (XRD)}

XRD patterns of the samples with size fractions $<2 \mu \mathrm{m}$ and under different experimental conditions (oriented at room temperature, ethylene glycol, at $350^{\circ} \mathrm{C}$ and $550^{\circ} \mathrm{C}$ ) are presented in Fig. 3 . The results indicated that minerals of kaolin group are identified by the basal spacing at typical peaks of 7.18-7.42 Á, $4.44 \AA$ và 3.59 Á. The basal reflections of $10 \AA$ halloysite are recorded at peaks of $10.0 \AA$ and $4.4 \AA$ (Mineralogy Database). The broad and weak basal reflection at $7.42 \AA$ indicates that $7 \AA \AA$ halloysite and kaolinite coexist in the sample (Brindley, 1980). A shift of the 7.42 to $7.18 \AA$ peak together with a small intensity increase of the $3.59 \AA$ peak as well as the change of the $10.0 \AA$ to $10.6 \AA$ peak under condition of treatment with EG also referred to halloysite mineral in the sample (Hillier \& Ryan, 2002). At heating condition of $350^{\circ} \mathrm{C}$, the $(001)$ peaks of 10 Á and $7 \AA$ Á halloysite minerals were shifted to the
(001) peak of kaolinite mineral (7.18 Á). This may be due to the loss of water in the halloysite layers. At $550^{\circ} \mathrm{C}$ condition, the structures of halloysite and kaolinite minerals were destroyed and turned into the amorphous phase.

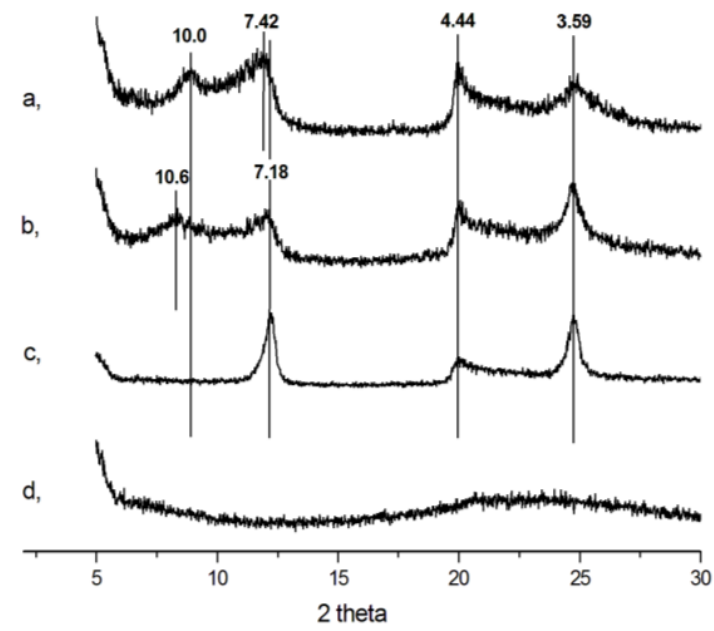

Fig. 3. XRD patterns of the sample of the size fraction $<2 \mu \mathrm{m}$ under 4 different conditions: oriented at room temperature (a,), ethylene glycol (b,), at $350^{\circ} \mathrm{C}(\mathrm{c}$,$) and at 550^{\circ} \mathrm{C}(\mathrm{d}$,

\subsection{Scanning Electron Microscope (SEM)}

Fig. 4 shows the SEM images of nanotubular halloysite mineral in different view scales (40, 10 and $5 \mu \mathrm{m})$ and its point EDS result. From Fig.4A, it can be seen that a cotton layer coats on the surface of the sample. This layer can be observed more clearly in Fig. 4B and 4C with set of mess rodshape crystals. These are the tubular crystals of halloysite minerals and their length can be up to $5 \mu \mathrm{m}$. Point EDS pattern of this mineral shows the peaks of $\mathrm{Al}$ and $\mathrm{Si}$ elements which matches the chemical composition of halloysite mineral formula of $\mathrm{Al}_{2} \mathrm{Si}_{2} \mathrm{O}_{5}(\mathrm{OH})_{4} \cdot 2 \mathrm{H}_{2} \mathrm{O}$ (Figure $4 \mathrm{C}$ and 4D). Result of semi-quantitative analysis for size fractions $<2 \mu \mathrm{m}$ using EDS is presented in table 1. The major compositions comprise $\mathrm{SiO}_{2}$ and $\mathrm{Al}_{2} \mathrm{O}_{3}$, while the concentrations of other oxides such as $\mathrm{Na}, \mathrm{Mg}, \mathrm{K}, \mathrm{Ca}, \mathrm{Ti}, \mathrm{Fe}$ are low. 
Vietnam Journal of Earth Sciences 37 (2015) 299-306
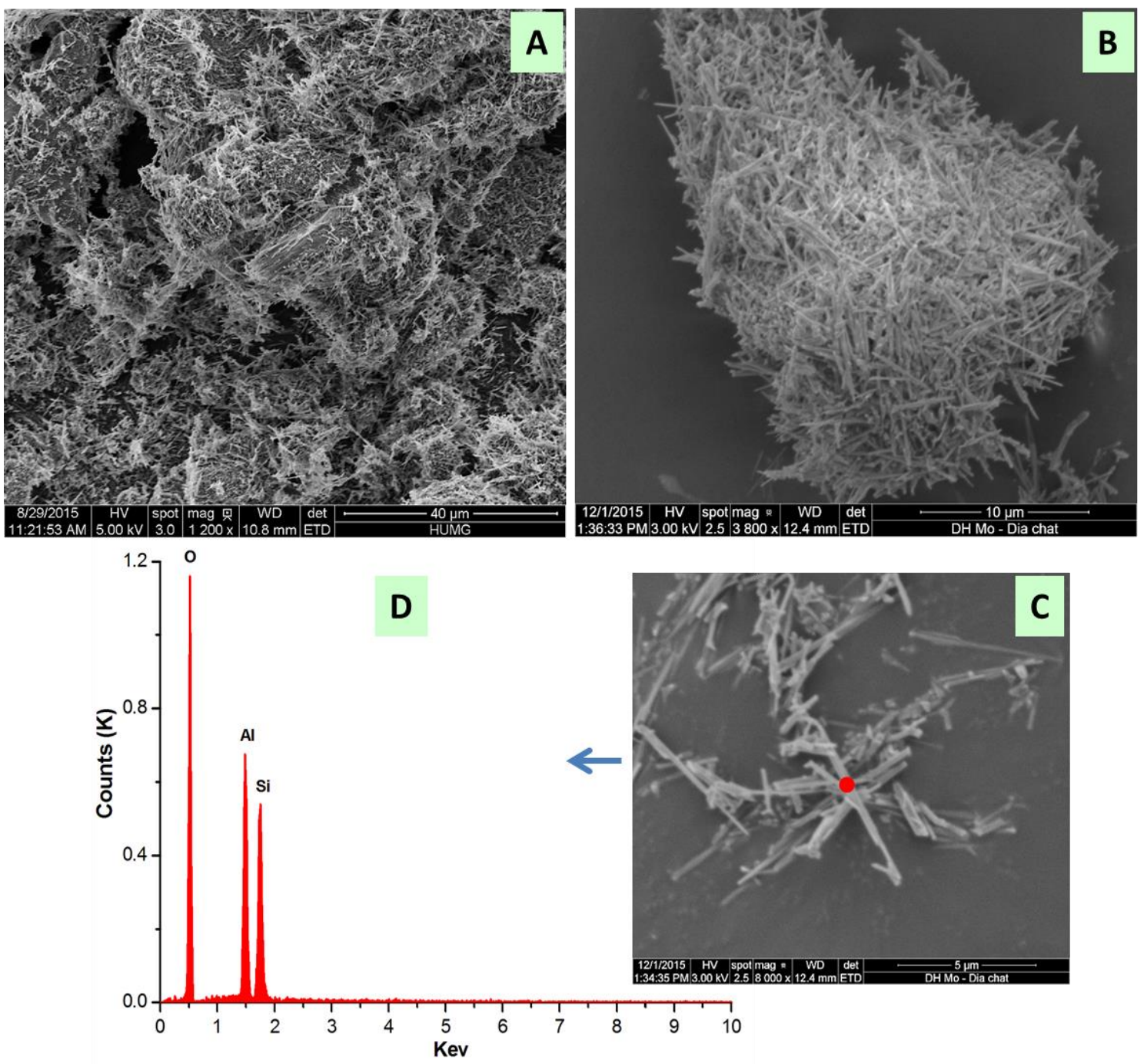

Fig. 4. SEM images of nanotubular halloysite at different view scales of $40 \mu \mathrm{m}(\mathrm{A}), 10 \mu \mathrm{m}(\mathrm{B}), 5 \mu \mathrm{m}(\mathrm{C})$ and EDS pattern of halloysite (D)

Table 1. Semi-quantitative analysis for size fraction $<2 \mu \mathrm{m}$ using SEM-EDS

\begin{tabular}{llll}
\hline $\begin{array}{c}\text { Size } \\
\text { fraction }\end{array}$ & \multicolumn{3}{c}{ Concentration of oxides (\%) } \\
\hline$<0.2 \mu \mathrm{m}$ & $\frac{\mathrm{Na}_{2} \mathrm{O}}{0.06} \frac{\mathrm{MgO}}{0.33} \frac{\mathrm{Al}_{2} \mathrm{O}_{3}}{46.45} \frac{\mathrm{SiO}_{2}}{52.17} \frac{\mathrm{K}_{2} \mathrm{O}}{0.5} \frac{\mathrm{CaO}}{0.16} \frac{\mathrm{TiO}_{2}}{0.29} \frac{\mathrm{Fe}_{2} \mathrm{O}_{3}}{0.38}$ \\
\hline
\end{tabular}

\subsection{Transmission Electron Microscopy (TEM)}

Fig. 5 shows the transmission electron micrographs of halloysite. It clearly indicates that halloysite at the Lang Dong deposit have nanotubular shapes. These structures consist of cylindrical tubes with diameter of $0.08 \div 0.30 \mu \mathrm{m}$ and length of 0.60 to $6.00 \mu \mathrm{m}$. The distributions of the lengths and outer diameters of halloysite using TEM images are presented in Fig 6. Results showed that nanotubular halloysite in Lang Dong deposit distributed mainly in the length of $2 \div 4 \mu \mathrm{m}$ and the outer diameter of $0.1 \div 0.2 \mu \mathrm{m}$. The mean diameter and length are 0.17 and $2.48 \mu \mathrm{m}$, respectively. 
B. H. Bac and N. T. Dung/Vietnam Journal of Earth Sciences 37 (2015)

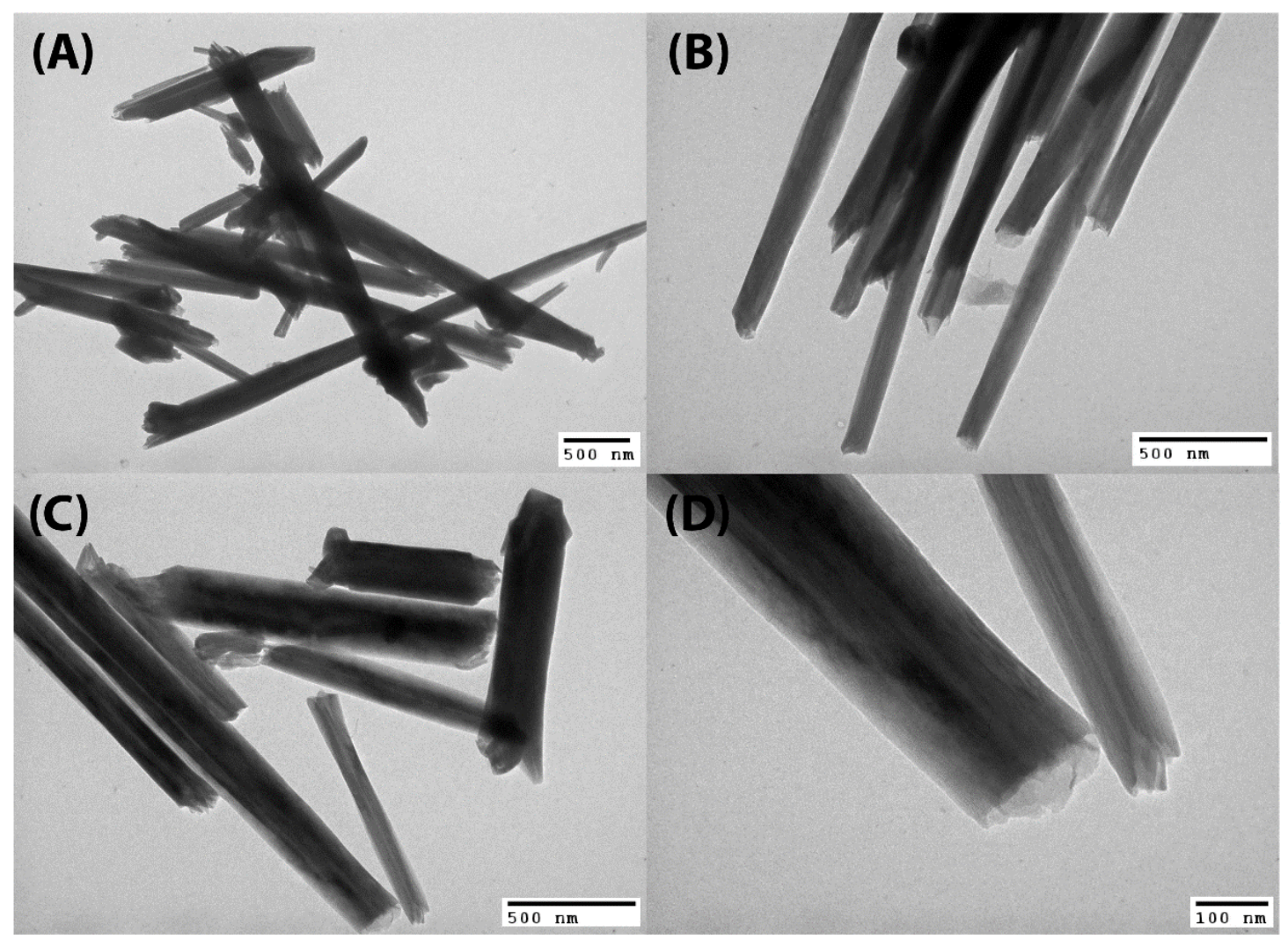

Fig. 5. TEM images of nanotubular halloysite at different direction magnifications (Direct magnifications of 5000x (A), 10000x (B), 10000x (C) and 30000x (D)
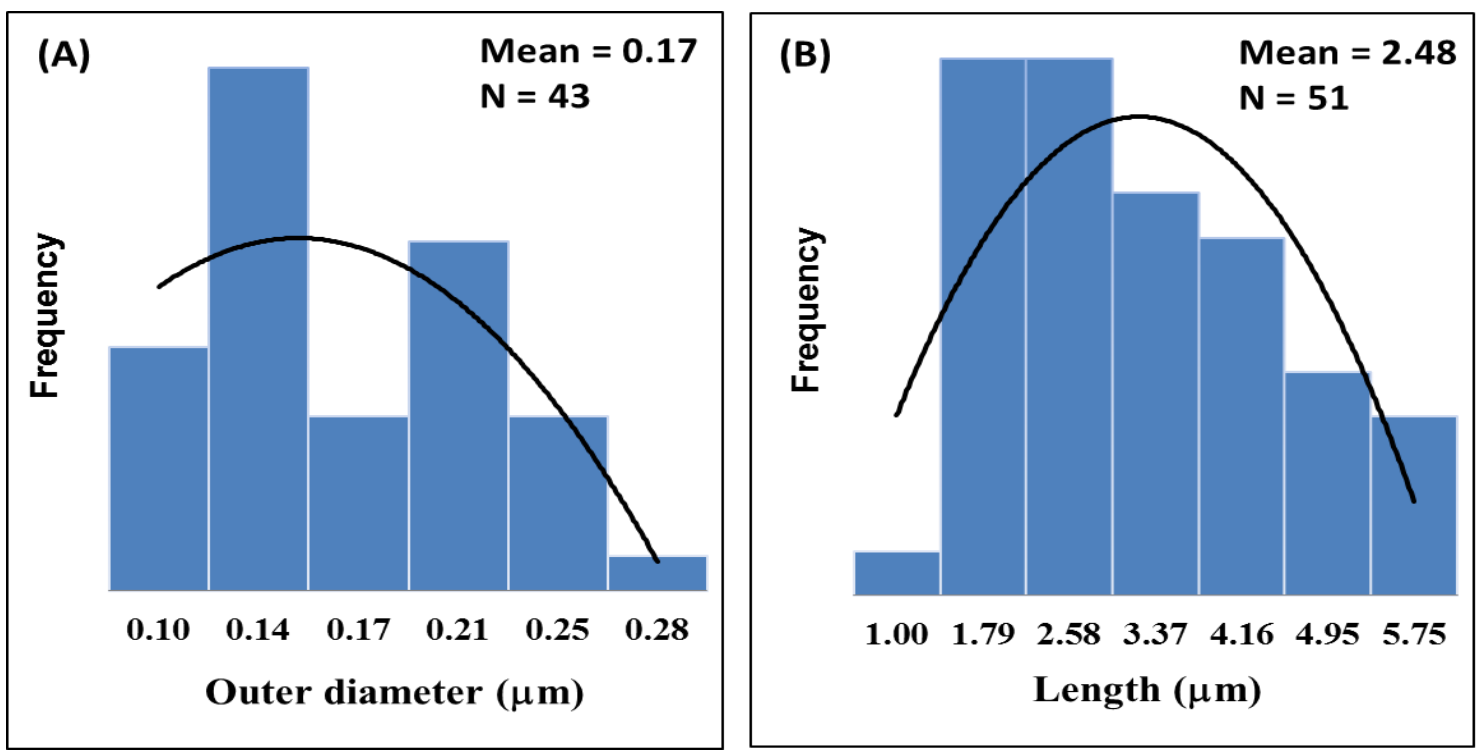

Fig. 6. The distributions of the lengths and outer diameters of halloysite from TEM (A). Outer diameter; (B). Length 
Vietnam Journal of Earth Sciences 37 (2015) 299-306

\subsection{Semi-quantitative analysis of nanotubular} halloysites

Formamide (FA) is a chemical substance that has the formula of $\mathrm{CH}_{3} \mathrm{NO}$. It can be intercalated into halloysite structures of varying composition. However, FA is intercalated into kaolinite very slowly (Churchman \& Theng, 1984). This difference provides a simple test to distinguish two minerals and can also be used for the semiquantitative estimation of halloysite and kaolinite ratio. Fig. 7 shows the XRD patterns of the sample before and after treating with FA within 30 minutes. It can be observed that after FA intercalation, halloysites show the peak of $10 \AA$
$(10.3 \AA$ Á) and kaolinites present the peak of $7 \AA$ (7.2 $\AA$ ). The degree of FA intercalation was assessed from the ratio of the intensity of the appropriate basal reflections. The degree of intercalation is given by the ratio $\alpha=\mathrm{I}_{10} /\left(\mathrm{I}_{7}+\mathrm{I}_{10}\right)$ where $I_{7}$ and $I_{10}$ denote the intensity of the peaks near 7 and $10 \AA$, respectively. The percentage of halloysite in a given sample was obtained by multiplying the corrected ratio by 100 (Churchman $\&$ Theng, 1984). In this experiment, the values of $I_{10}$ and $I_{7}$ were defined as 69 and 66 counts, respectively. So $\alpha$ is calculated as 0.51 . The estimated percentage of halloysite in the sample with size fractions $<2 \mu \mathrm{m}$ is approximately $50 \%$.

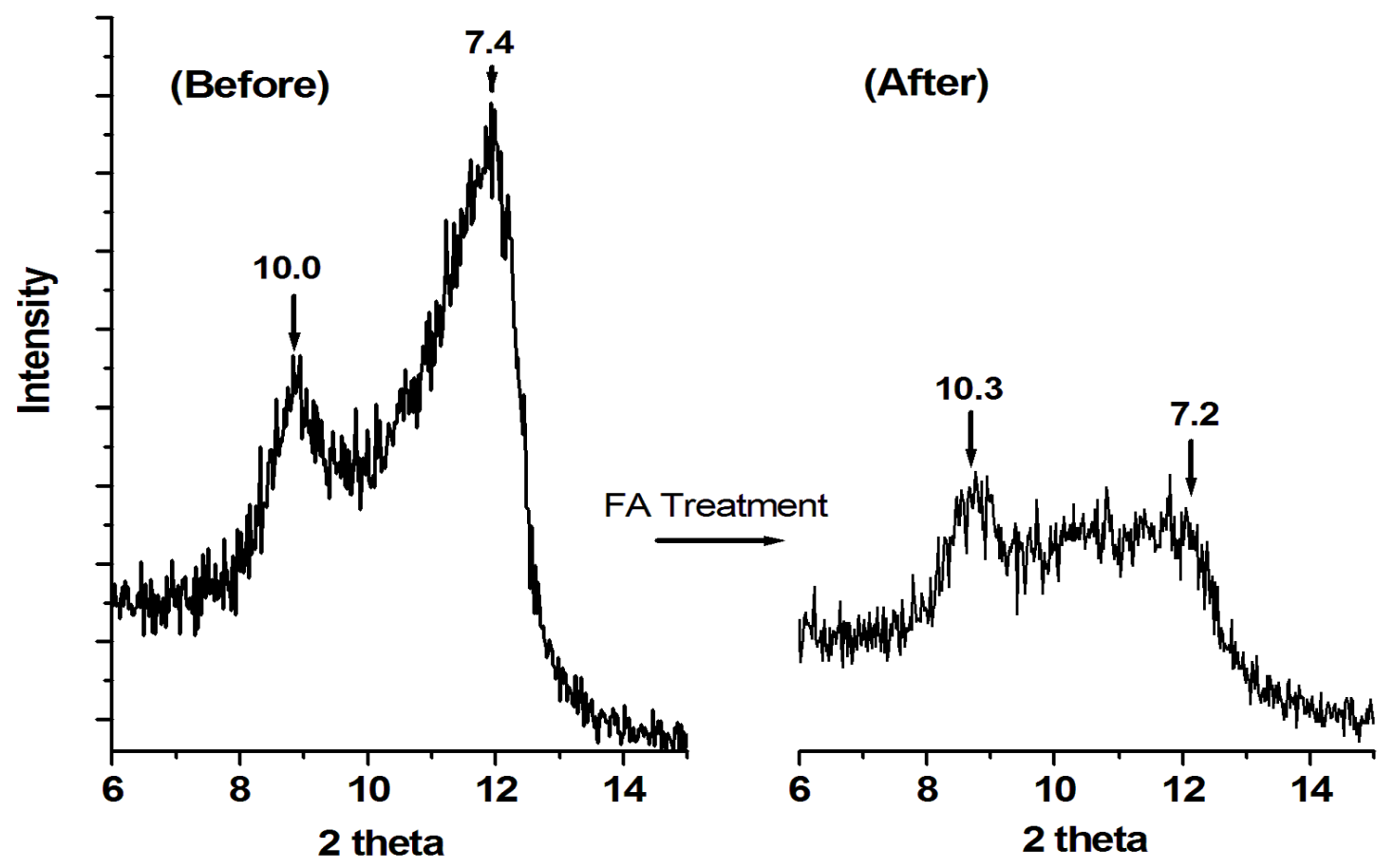

Fig. 7. XRD patterns of halloysite sample before and after FA treatment

\section{Conclusion}

In conclusion, the bulk sample collected from Lang Dong kaolin deposit, Phu Tho province was separated into size fractions $<2 \mu \mathrm{m}$ using decantation method. The samples were then characterized by X-ray diffraction (XRD), scanning electron microscopy (SEM), and transmission electron microscopy (TEM). The results indicated that clay minerals in the samples are mainly halloysite and kaolinite. The halloysite has hollow nanotubular structures with typical outer diameter of $0.08 \div 0.30 \mu \mathrm{m}$ and length of $0.60 \div 6.00 \mu \mathrm{m}$. The mean outer diameter and length are 0.17 and $2.48 \mu \mathrm{m}$, respectively. The major compositions are $\mathrm{SiO}_{2}$ and $\mathrm{Al}_{2} \mathrm{O}_{3}$, while the concentration of other oxides such as $\mathrm{Na}, \mathrm{Mg}, \mathrm{K}$, $\mathrm{Ca}, \mathrm{Ti}, \mathrm{Fe}$ are low. Approximately $50 \mathrm{wt} \%$ of the $<2 \mu \mathrm{m}$ size fraction is halloysite. The obtained results may be used to clarify the characteristics of 


\section{B. H. Bac and N. T. Dung/Vietnam Journal of Earth Sciences 37 (2015)}

mineral composition in the Lang Dong kaolin deposit, thereby allowing for more efficient use of this resource.

\section{Acknowledgements}

This research is financially supported by the Vietnam National Foundation for Science and Technology Development (NAFOSTED) under grant number 105.03-2011.11 to Bui Hoang Bac.

\section{References}

Berthier, P., 1986: Analyse de I'halloysite. Annales de Chimie et de Physique 32, 332-335.

Chipera, S.J., \& Bish, D.L., 2002: FULLPAT: a full pattern quantitative analysis program for X-ray powder diffraction using measured and calculated patterns. Journal of Applied Crystallopgraphy 35 (2002) 744-749.

Churchman, G.J., 2000: The alteration and formation of soil minerals by weathering. F3-F76 in: Handbook of Soil Science (M.E. Sunner, editor). CRC Press, Boca Ration, Florida.

Churchman, G.J., Carr, R.M., 1972: Stability fields of hydration states of a halloysite. American Mineralogist 57, 914-923.

Churchman, G.J., Carr, R.M., 1975: The definition and nomenclature of halloysites. Clays and Clay minerals 23 , 382-388

Churchman, G.J. and Theng, B.K.G., 1984: Interactions of halloysites with amides: mineralogical factors affect-ing complex formation. Clay Minerals 19, 161-175.

Deepak, R., \& Agrawal, Y.K., 2012: Multifarious applications of halloysite nanotubes: A review. Reviews on Advanced Materials Science 30, 282-295.

Ghanbari, M., Emadzadeh, D., Lau, W.J., Matsuura, T., Ismail, A.F., 2015: Synthesis and characterization of novel thin film nanocomposite reverse osmosis membranes with improved organic fouling properties for water desalination. RSC Advances 5, 21268-21276.

Hillier, S., Ryan, P.C., 2002: Identification of halloysite (7尺́) by ethylene glycol solvation: the 'MacEwan effect'. Clay minerals $37,487-496$.

Joussein, E., Kruytz, N., Righi, D., Petit, S., Delvaux, B., 2004:
Specific retention of radiocesium in volcanic ash soils devoid of micaceous clay minerals. Soil Science Society of America Journal 68, 313-319.

Kohymna, N., Fukushima, K. and Fukami, A., 1978: Observation of the hydrated form of tubular halloysite by an electron microscope equipped with an environmental cell. Clays and Clay Minerals 26, 25-40.

Mineralogy database: http://webmineral.com/data/Halloysite.shtml\#.VmqAFtJ97 RZ .

Mingliang, D., Baochun, G., Demin, J., 2010: Newly emerging applications of halloysite nanotubes: A review. Polymer International 59, 574-582.

Nicolini, K.P., Fukamachi, C.R.B., Wypych, F., and Salvio M.A.S., 2009: Dehydrated halloysite intercalated mechanochemically with urea: Thermal behavior and structural aspects. Journal of Colloid and Interface Science $338,474-479$

Nguyen, T.D., \& Nguyen, P., 2006: Geological characteristics and quality of kaolin, feldspar in Thach Khoan area, Thanh Son, Phu Tho. Journal of Mining \& Geology Science and Technology 15(7) 65-70 (in Vietnamese).

Poppe, L.J., Paskevich, V.F., Hathaway, J.C., and Blackwood, D.S., 2001: A laboratory manual for X-ray powder diffraction. U.S. Geological Survey Open-File Report 01041, pp. 88 .

Ravindra, K., Manasi, G., Sheetal, G., Bijoy, K.P., 2012: Halloysite nanotubes and applications: A review. Journal of advanced scientific research 3(2) 25-29.

Sunaree, B., Darunee, B., Thongchai, P., Tripob, B., 2011: Characterization ò halloysite from Thung Yai District, Nakhon Si Thammarat Province, in southern Thailand. Songklanakarin Journal of Science and Technology 33(5), 559-607.

Wada, S.I., \& Mizota, C., 1982: Iron-rich halloysite (10§́) with crumpled lamellar morphology from Hokkaodo, Japan. Clays and Clay minerals 30, 315-317.

Yariv, S. and Shoval, S., 1976: Interaction between alkalihalides and halloysite: I.R. study of the interaction between alkali-halides and hydrated halloysite. Clays and Clay Minerals 24, 253-561. 